\title{
Anatomical Characteristics of Petalized Anther Abortion in Male Sterile Camellia oleifera Plants
}

\author{
Yang Hu, Chao Gao, Quanen Deng, Jie Qiu, Hongli Wei, Lu Yang, and Jiajun Xie \\ Institute for Forest Resources and Environment of Guizhou, Key Laboratory of Forest Cultivation \\ in Plateau Mountain of Guizhou province, College of Forestry, Guizhou University, Guiyang \\ 550025, China \\ Desheng Liao \\ Guizhou Southwest Karst Regional Development Institute, Xingyi 562400, China
}

\begin{abstract}
ADDITIONAL INDEX WORDS. angiosperm, male sterility, paraffin section, petaloid anther
Abstract. Petalized anther abortion is an important characteristic of male sterility in plants. The male sterile plants (HB-21) evincing petalized anther abortion previously discovered in a clone population of the Camellia oleifera cultivar Huashuo by our research group were selected as the experimental material in this study. Using plant microscopy and anatomic methods and given the correspondence between external morphology and internal structure, we studied the anatomic characteristics of petalized anther abortion (with a fertile plant as the control group) in various stages, from flower bud differentiation to anther maturity, in hopes of providing a theoretical basis for research on and applications of male sterile $C$. oleifera plants, a new method for the selection of male sterile $\boldsymbol{C}$. oleifera cultivars, and improvements in the yield and quality of $C$. oleifera. In this study, the development of anthers in $C$. oleifera was divided into 14 stages. Petalized anther abortion in male sterile plants was mainly initiated in the second stage (the stage of sporogenous cells). Either the petalized upper anther parts did not form pollen sacs, or the entire anthers did not form pollen sacs. The lower parts of some anthers could form deformed pollen sacs and develop, and these anthers could be roughly divided into two types: fully and partially petalized anthers. Abnormal callose and the premature degradation of the tapetum occurred in the pollen sacs formed by partially petalized anthers during the development process, resulting in the absence of inclusions in the pollen grains formed. Small quantities of mature pollen grains withered inward from the germinal furrows, exhibiting obvious abortion characteristics. The relative in vitro germination rate of the pollen produced by the partially petalized anthers of sterile plants was $11.20 \%$, and the relative activity of triphenyltetrazolium chloride was $3.24 \%$, while the fully petalized anthers did not generate pollen grains. Either the petalized anthers in male sterile plants did not produce pollen, or the vitality of the small amounts of pollen produced by sterile plants was very low compared with that of fertile plants. Such male sterile plants could be used to select correct clones and have good prospects for application in production.
\end{abstract}

C. oleifera is an evergreen shrub or small arbor in the Theaceae family. It is mainly distributed in mountainous and hilly areas in southern China. It is also known as one of the world's four major woody edible oil plants along with olive (Olea europaea), oil palm (Elaeis guineensis), and coconut (Cocos nucifera). Camellia oil, rich in unsaturated fatty acids and vitamin E, is called "eastern olive oil" worldwide (Gao et al., 2018; Zhang et al., 2008; Zhuang, 2008). At present, up to 4.5 million hectares of $C$. oleifera is planted in China. The successful cross-fertilization and fruit setting of $C$. oleifera depends on insect pollinators. In addition to the biological characteristics of pollination, the high-yield and efficient development of $C$. oleifera are also subject to cultivar selection, cultivation technology, and management (Wen et al., 2018). The size and quantity of the

Received for publication 17 May 2021. Accepted for publication 30 July 2021. Published online 23 September 2021.

This work was supported by the National Natural Science Foundation of China (31800516, 32060331), Science and Technology Planning Projects of Guizhou (Qian Ke He [2019]2310, Qian Ke He [2020]1Y057, [2018]5781, Qian Ke He Fu Qi [2020]4011), Science and Technology Project of Guizhou Education Department (Qian jiao He KY[2018]097, Qian jiao He KY[2019]022), Cultivation Project of Guizhou University ([2019]35), and Research Project of Introducing Talents in Guizhou University ([2017]41). We would like to thank Mr. Lu Shikui for his assistance in sampling.

C.G. is the corresponding author. E-mail: gaochao@gzu.edu.cn.

This is an open access article distributed under the CC BY-NC-ND license (https://creativecommons.org/licenses/by-nc-nd/4.0/). seeds produced by $C$. oleifera also display large differences (Xiao et al., 2015). Cultivating and popularizing elite cultivars of C. oleifera are the main methods used to increase the production of $C$. oleifera.

In the agricultural field, the use of male sterile materials in hybrid breeding to cultivate elite cultivars with heterosis has contributed greatly to an increase in crop production (Yuan, 2017). The flower of $C$. oleifera is bisexual, and the male sterile plant serves as the female parent. Selecting a suitable male parent and then planting the male and female parents according to a proper proportion can make the male sterile plant accept target pollen in a natural pollination manner at the lowest cost; this strategy will undoubtedly accelerate the process of $C$. oleifera breeding (Xiong et al., 2019). Therefore, exploring the mechanism of male sterility in plants has always been a hot spot in the field of botany. Usually, in research on male sterility, cell biology studies on aborted anther development are indispensable and are the first studies conducted, as these studies can reveal the association of the molecular mechanism of anther abortion with the regulation of the phenotypes of individual plants (Xie et al., 2006). During the development of anthers, the normal functioning of tissue cells at various stages, such as the differentiation of sporogenous cells to form pollen mother cells, the degradation of callose wrapped by pollen mother cells, and the timely decomposition of the tapetum that supplies nutrients for microspores, is a prerequisite for the production of fertile pollen 
(Hu, 2005). Otherwise, the abnormal functioning of these cells may lead to male sterility. Anther abortion is mainly manifested in morphology as anther browning or petalized anthers (Carlsson and Glimelius, 2011; Jia et al., 2020). In male sterile Daucus carota plants, petaloid anthers can retain parental traits more easily than brownish anthers (Kozik et al., 2012). To date, petaloid abortion has been found in Allium schoenoprasum, Brassica juncea, Tagetes patula, and D. carota (Engelke et al., 2002; He et al., 2010; Kozik et al., 2012; Meur et al., 2006); however, the mechanisms of abortion are diverse and can include the abnormal development of the connective tissues and pollen sacs that constitute anthers.

In the early stage of research, our research team found a male sterile plant with significant anther mutations and a serious petalization phenomenon in a natural clone population of the C. oleifera cultivar Huashuo. This was the first time that a male sterile mutant individual was found in the nationally approved cultivar of $C$. oleifera that is widely popularized in China. Compared with the genetic engineering of male sterility, the safety of male sterile plants found in natural populations is more compelling (Ai et al., 2014). The development of common C. oleifera, starting in early May and continuing to November each year, is characterized by a long duration and complicated process (Lei et al., 2017). As of now, the abortion period and mechanism of the male sterile $C$. oleifera plants remain unclear. An understanding of the main period and method of its abortion will pave the way for further studies on the molecular biological mechanism of sterility and applications of male sterile plants to the production of $C$. oleifera as soon as possible. Male sterile C. oleifera plants found early cannot be directly applied to production due to the small sizes of their wild populations, low yields, and long breeding cycles. However, male sterile $C$. oleifera plants have been of great importance in boosting the production of $C$. oleifera (Chen et al., 2011; Xiong et al., 2019).

Ordinarily, C. oleifera blooms in autumn and winter. The pistils and stamens bloom and mature synchronously. The stigmas are wrapped in anthers. The pollen, after being dispersed from the anthers, directly comes into contact with the stigmas. As ordinary $C$. oleifera has self-incompatibility in the late stage, a self-incompatibility reaction occurs at the base of each style. The ovary eventually falls off. This botanical characteristic is one of the important causes of the low fruit-setting rate and low yield of C. oleifera (He et al., 2020; Liao et al., 2014). In crop production, self-compatible plants call for line (cultivar) selection to improve the fruit-setting rate, and after pollination, the selection of cultivars with the best compatibility can improve the fruit and seed quality (Bulant and Gallais, 2000; Hu et al., 2020; Klatt et al., 2014; Kodad, 2008; Liu et al., 2010; Pahlavani and Abolhasani, 2006). At present, research on the $C$. oleifera cultivar Huashuo has been carried out (Hu et al., 2020). However, in production practice, determining how to make the pollinizer pollinate more female parents of the main cultivar presents a research issue. The male sterile plants do not produce pollen or produce minimal pollen, thereby ensuring the cross-pollination rate and allowing reasonable line (cultivar) selection so that the male sterile plants can receive more pollen from the target pollinizer. Based on many years of fixed-point observations, we intended to use plant microscopy technology to conduct an observation and analysis of the external morphology and internal structure of the male sterile plants (with a fertile plant as a control) from flower bud differentiation to anther maturity in hopes of providing a theoretical basis for research on and the application of male sterile plants of $C$. oleifera.

\section{Materials and Methods}

\section{Experimental materials}

The experimental materials were planted at the $C$. oleifera Research Station of Guizhou University [Dongcheng Town, Wangcheng District, Changsha City, Hunan Province (lat. $113^{\circ} 21^{\prime} \mathrm{E}$, long. $\left.28^{\circ} 05^{\prime} \mathrm{N}\right)$ ]. The research base has an annual average precipitation of $1380 \mathrm{~mm}$, an annual average temperature of $19.3^{\circ} \mathrm{C}$, an annual accumulated temperature of $5463^{\circ} \mathrm{C}$, an annual average frost-free period of 276 to $291 \mathrm{~d}$, and an annual average sunshine duration of $1762 \mathrm{~h}$. The study area has sufficient light and heat conditions, a short winter cold period, and is of a typical midsubtropical monsoon humid climate. The soil is red soil with medium fertility, with a $\mathrm{pH}$ value of $\approx 5.5$. Conventional water and fertilizer management was applied to the soil. The male sterile plants (HB-21) found in the C. oleifera cultivar Huashuo and the normal fertile male plants (CK) of this cultivar were used as the samples for the flower bud collection.

\section{Experimental methods}

SAMPLING. To determine the stability of the characters of the sterile $C$. oleifera plants, we collected samples during the reproductive growth period for 4 consecutive years from 2017 to 2020 , on the basis of previous research. The samples included the flower buds and floral organs of the sterile and fertile male plants $(\approx 1000$ flowers were collected each year).

OBSERVATION OF FLOWER BUD MORPHOLOGY. The flower buds and anthers were observed and photographed using a stereomicroscope (S9I; Leica, Wetzlar, Germany) (the scales were peeled off, and the anthers were removed with forceps). The flower buds and anthers that exhibited signs of petalized abortion were taken as the focus for further descriptions.

OBSERVATION OF THE INTERNAL MORPHOLOGY OF FLOWER BUDS AND THE MICROSTRUCTURE OF ANTHER DEVELOPMENT. The method in this study was slightly improved with reference to the methods described by Gao et al. (2015a). After the flower buds were removed from the tree, they were immediately put into Carnoy's fluid [glacial acetic acid: $95 \%$ ethanol $=1: 3(\mathrm{v} / \mathrm{v})$ ] for desiccation, fixed for $20 \mathrm{~h}$, transferred to a $70 \%$ ethanol solution, and stored in a refrigerator at $4{ }^{\circ} \mathrm{C}$ for later use. The fixed materials were made into samples by intact staining with hematoxylin and were washed, dehydrated, cleared, permeated, embedded, and sliced using a microtome (RM2235, Leica). The thickness of each slice was $8 \mu \mathrm{m}$. After bonding, dewaxing, and sealing, the slices were photographed under an optical microscope (DM2500, Leica).

SCANNING ELECTRON MiCroscope OBSERVATION. The collected samples were trimmed to sections for observation, fixed with $2.5 \%$ glutaraldehyde fixative solution for $4 \mathrm{~h}$, washed with phosphate buffer, and then fixed with $1 \%$ osmic acid fixative solution for $3 \mathrm{~h}$; then, the samples were washed and dehydrated in a graded acetone solution, transferred to tertiary butanol, frozen, and dried. Each sample was placed on the sample stage and then placed into an ion sputtering instrument (MSP-mini; IXRF, Austin, TX) for gold plating for $20 \mathrm{~s}$. A scanning electron microscope (SEM) (TM4000Plus; Hitachi, Ibaraki, Japan) was used to observe and photograph the samples. 
Detection of Pollen vitality. With reference to the methods outlined in He et al. (2009), we used 0.5\% triphenyltetrazolium chloride (TTC) buffer solution and a culture medium (10 $\mathrm{g} \cdot \mathrm{L}^{-1}$ agar $+0.1 \mathrm{~g} \cdot \mathrm{L}^{-1}$ boric acid $+100 \mathrm{~g} \cdot \mathrm{L}^{-1}$ sucrose solution) combined with the in vitro germination method to detect the pollen vitality. According to the type of anther development, the fully petalized pollen, partially petalized pollen, and normal pollen produced by the anthers of male sterile plants were used in the experimental group, whereas the pollen produced by the anthers of the normal fertile male plants was used as the control group. For each type, 10 flowers were collected in the full blooming period, and their pollen was pooled. Each group had three culture mediums. Four fields of view were randomly selected for each medium and photographed with an optical microscope (DM2500).

\section{Results}

TyPES OF PETALIZED ANTHER ABORTION OF MALE STERILE PLANTS. The $C$. oleifera cultivar Huashuo blooms mainly from late October to early December, and the full blooming period is concentrated in mid-November. When the floral organs are open, from a structural point of view, the multilayered stamens in the floral organs of normal fertile plants wrap around the pistil to form a stamen cluster. The anthers are slightly higher than the stigma, and the anthers are yellow when they are mature and dispersed (Fig. 1A1, B1, and C1). The anthers have four full and normal pollen sacs (Fig. 1D1). The main feature of male sterility is that no pollen is produced or that the pollen produced is not viable. Male sterile $C$. oleifera plants can produce fully petalized anthers (Fig. 1A3, B3, and C3), partially petalized anthers, or small amounts of normal anthers with no deformation in appearance (Fig. 1A2, B2, and C2). Morphologically, the upper parts of partially petalized anthers undergo a petalized mutation, showing albino characteristics similar to those of petals. Small numbers of pollen sacs were observed near the ends of filaments; these sacs could produce pollen and release pollen grains. The degree of petalization of the petaloid area of anthers in the inner ring in this type of flower organ was greater than that of the anthers in the outer ring. The anthers in the outer ring were smaller than those in the inner row, and a few anthers in the outer ring were unchanged in appearance (Fig. 1D2). In sterile plants, the anthers of the fully petalized flower organs had no pollen sacs, and no pollen was produced. In each of these plants, the entire anther was shaped like a petal, and the stamens were in an imbricate arrangement (Fig. 1B3, C3, and D3).

ANTHER FORMATION OF MALE STERILE PLANTS AND EARLY MORPHOLOGY OF PETALIZED ANTHERS. At the stage of flower bud differentiation, the flower buds of sterile plants (Fig. 2A1-A6) and fertile plants (Fig. 2E1-E6) showed no obvious difference in external morphology. The SEM observations showed that the male sterile plants (Fig. 2B1 and C1) and the fertile plants (Fig. $2 \mathrm{~F} 1$ and $\mathrm{H} 1$ ) were in the early stage of pistil and stamen formation. The stamens formed a circle of small protrusions of stamen primordia around the center of each receptacle, and these protrusions obviously differed in morphology from the surrounding cells (Fig. 2D1 and H1). Then, a pistil formed in the center of each receptacle (Fig. 2B2 and F2).

The development of stamens in a ring surrounding to the pistil occurs slightly earlier than the stamen development in the other outer rings (Fig. 2C2, D2, G2, and H2). The flower buds were observed developing further, while the petal layers gradually increased (Fig. 2B3 and F3). The pistil and stamens also developed further, the stamens in the inner ring were fingershaped (Fig. 2C3 and G3), and the stamens formed three rings. Before this stage, no obvious morphological difference was present between the sterile plants and the fertile plants. With the progressive development of the fertile plants, the three stamen rings that had formed began to expand significantly at the top (Fig. 2F4, G4, and H4), and the stamens of the innermost ring next to the pistil in the sterile plants gradually showed signs of flattening (Fig. 2B4, C4, and D4). The development of the stamens in the innermost rings of the fertile plants was better than that of the other stamens (Fig. 2F5 and G5), with the top of the anthers continuing to expand, forming four obvious corners (Fig. 2H5), and the tops of the stamens of the sterile plants differentiated into anthers (Fig. 2B5). The upper parts of the anthers were flat, and the lower parts of the anthers expanded to form corners of pollen sacs (Fig. 2C5 and D5). The pollen sacs of the fertile plants further developed and enlarged, and an obvious shadow appeared at each junction of the two pollen sacs on the same side (Fig. 2F6, G6, and H6). In subsequent development, the morphology of the anthers had already formed, only showing an increase in size (Fig. 2I5 and J5). In the lower parts of the anthers of the sterile plants, four obvious pollen sacs were observed (Fig. 2B6 and C6); however, the widths of the outer pollen sacs were smaller than those of the inner pollen sacs, and the upper parts of the anthers were further flattened (Fig. 2D6). In subsequent development, the anthers of the sterile plants could be divided into three types in terms of their morphological and structural characteristics: the fully petalized type (Fig. 2I4), partially petalized type (Fig. 2I1-I3), and (small numbers of) normal development type. No difference in morphology was detected between the normal anthers of sterile plants and the anthers of fertile plants. No pollen sacs were present in the upper parts of the partially petalized anthers, and the lower pollen sacs showed different shapes and sizes (Fig. 2J1-J3). The fully petalized anthers had no pollen sacs and were petal-shaped (Fig. 2J4). The external morphology and internal structural characteristics of petalized anther abortion in male sterile plants appeared after the formation of stamens at the flower bud differentiation stage, and no noticeable differences were observed between the sterile plants and fertile plants before this stage (Table 1).

Microstructure CHARACTERISTICS OF PETAlized ANTHER DEVELOPMENT. Through the longitudinal sections of the flower buds, it was observed that the stamen primordium cells elongated longitudinally where the flower buds were close to the petal primordia, making the small protrusions slightly higher than the plane of the receptacle (Fig. 3A1). One to two rings of small stamen protrusions were formed; only epidermal cells composed these small protrusions.

Anticlinal division was detected adapting the development of the stamens. The cell divisions on the underside of the epidermal cells were active, most of which were in the division phase, and the innermost ring developed earlier than the other rings (Fig. 3B1). After two to three rings of stamens had formed, the stamens expanded and were shaped like fingers (Fig. 3C1). Filament and anther differentiation occurred in the stamens of fertile plants. The cells located at the filaments elongated longitudinally, whereas the cells located at the anthers maintained their original shapes and continued dividing (Fig. 3D3 and D4) and the upper parts of the stamens of sterile plants remained flat (Fig. 3D1 and D2). An 

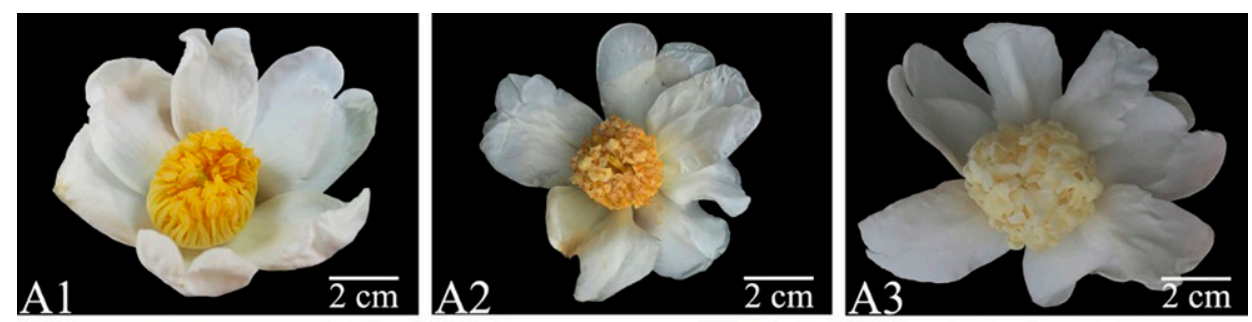

the connectivum (Fig. 3F3 and F4) was lightly stained. In contrast, the upper parts of the anthers of sterile plants were flat and lightly stained, and the pollen sacs in the lower parts of the anthers were darkly stained, displaying obvious morphological and structural differences (Fig. 3F1 and F2).
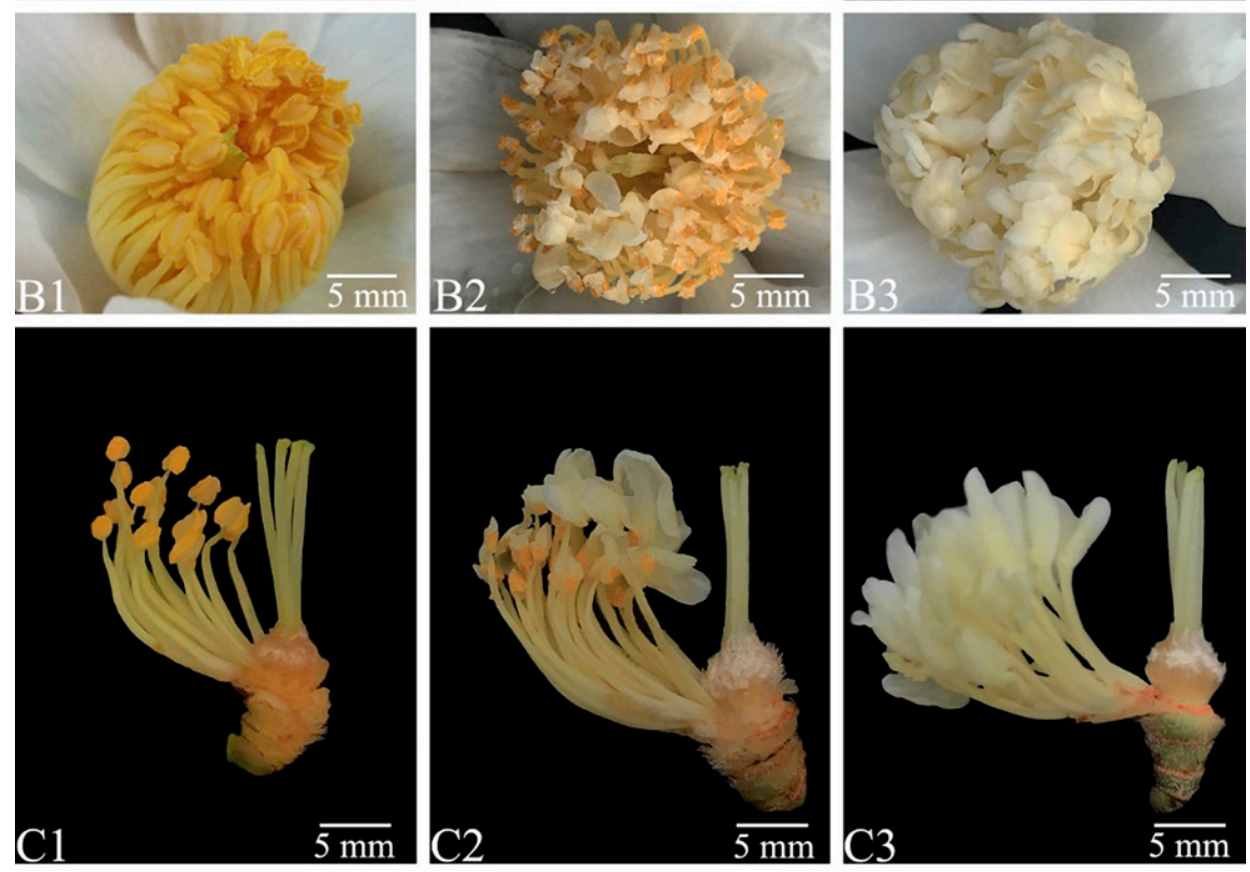

Microscopic OBSERVATIONS OF ANTHER DEVELOPMENT. To facilitate the description of the specific anther petalization period, this study divided the development of the anthers of fertile C. oleifera plants into the following 14 stages, which are described and analyzed in order:

1. When the stamen primordium had just formed, only three layers (labeled L3, L2, and L1 from the inside to the outside) of cells were present (Fig. 4A1). The outer layer mainly developed into the epidermis, the middle layer into sporogenous cells, and the inner layer into the connective tissue.

2. The stamen primordium underwent differentiation centered on the four corners, forming four pollen sac prototypes. The entire anther was darkly stained, and there was no differentiation between the connective tissue and pollen sac, but the sporogenous cells under the epidermis were observed to have large nuclei (Fig. 4A2).

3. Four pollen sacs were formed. The connective tissue formed by the L3 layer had light staining, whereas the pollen sacs showed dark staining (Fig. 4A3). The sporogenous cells underwent mitosis to form primary sporogenous cells and primary parietal cells. At this time, the anther wall had a total of two layers (Fig. 4A4).

4. The primary parietal cells

Fig. 1. Type of petalized anther abortion of male sterile Camellia oleifera plants and their morphological difference the anther possesses four complete pollen sacs. (A2-D2) Floral organ and anther morphology of partially petalized anthers of male sterile plants, with partially petalized anthers visible, showing that the upper parts are shaped like petals and the lower parts are still anthers. The anthers in the outer ring are small, and small numbers of unpetalized anthers express normal morphology. (A3-D3) Floral organ and anther morphology for fully petalized anthers of male sterile plants, with fully petalized anthers visible, showing albino petals with no visible pollen sacs.

obvious boundary between the anthers and filaments appeared in the stamen primordium of fertile plants, and no obvious difference was observed between the upper and lower parts of the longitudinal sections of the anthers (Fig. 3E3 and E4). An obvious boundary was detected between the upper and lower parts of the anthers in sterile plants, with the upper part being flat and the lower part having a pollen sac structure (Fig. 3E1 and E2). The anthers of fertile plants had two darkly stained pollen sacs, and the vascular tissue of underwent mitosis to produce two layers of secondary parietal cells and form three layers of anther parietal cells, and the differentiation of primary sporogenous cells produced secondary sporogenous cells (Fig. 4B1).

5. The two secondary parietal cell layers underwent mitosis at the same time or successively to form five layers of anther parietal cells: the epidermis (one layer), endothecium (one layer), middle layer (two layers), and tapetum layer (one layer) from the outside to inside. 

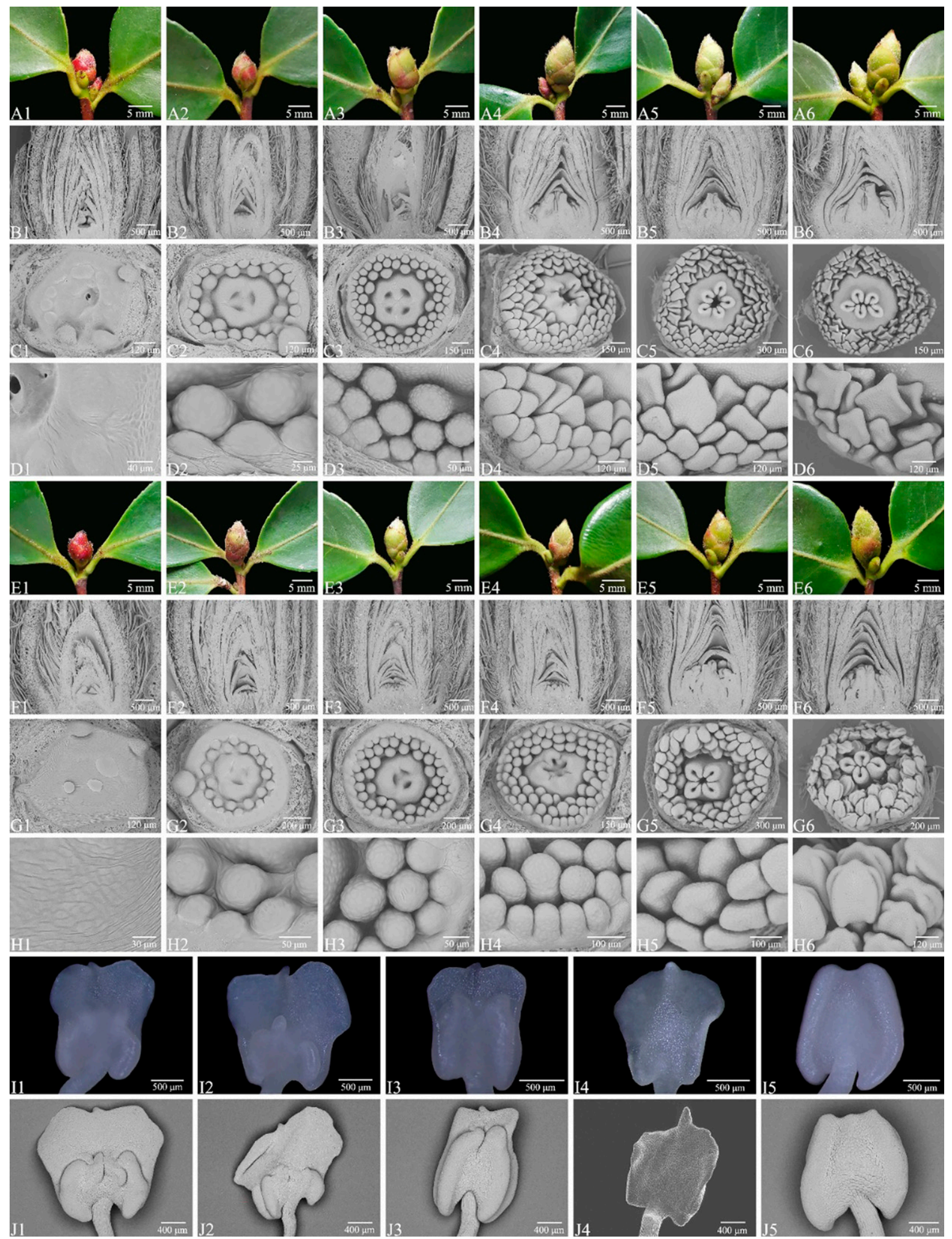

Fig. 2. Differences in stamen differentiation between sterile and fertile male Camellia oleifera plants. (A) External morphology of the flower buds of sterile plants. (B) Scanning images of the longitudinal sections of the flower buds of sterile plants. (C) Vertical scanning images of the flower buds of sterile plants with the sepals and petals removed. (D) Partial enlargement of (C). (E) External morphology of the flower buds of fertile plants. (F) Scanning images of the longitudinal sections of the flower buds of fertile plants. (G) Vertical scanning images of the flower buds of fertile plants with the sepals and petals removed. (H) Partial enlargement of (G). (I1-I3) Single partially petalized anthers of sterile plants. (I4) Single fully petalized anther of a sterile plant. (I5) Single anther of a fertile plants. (J1-J3) Single partially petalized anthers of sterile plants. (J4) Single fully petalized anther of a sterile plant. (J5) Single anther of a fertile plant. 
Table 1. Developmental process and differences in floral bud differentiation between sterile and fertile male Camellia oleifera plants.

\begin{tabular}{|c|c|c|}
\hline Date & Development process of stamens in fertile plants & Development process of stamens in sterile plants \\
\hline $20-28$ June & Stamen primordium cell cluster & \\
\hline 29 June-6 July & Stamen primordium slightly protruding from the receptacle & \\
\hline 7-13 July & All stamens formed, shaped like fingers & \\
\hline 22 July-2 Aug. & Butterfly-shaped pollen sacs & $\begin{array}{l}\text { The upper pollen sac was located outside } \\
\text { No pollen sacs formed }\end{array}$ \\
\hline
\end{tabular}

Secondary sporogenous cells proliferated through mitosis (Fig. 4B2).

6. The secondary sporogenous cells divided to form pollen mother cells surrounded by the common callosum. The tapetum layer developed, thickened, and acquired a dual-nucleus structure, and the middle layer changed into a ribbon-like shape (Fig. 4B3).

7. The pollen mother cells were ready to undergo meiosis. Callose underwent the first degradation to form a single pollen mother cell surrounded by callose, and the tapetum layer developed and thickened (Fig. 4B4).

8. The pollen mother cell completed meiosis I. Affected by this differentiation activity, the germ cell appeared in an ellipsoid shape (Fig. 4C1).

9. The pollen mother cell completed meiosis II and formed a tetrad surrounded by common callose. The tapetum layer developed and thickened and was ready to provide nutrition for the microspores (Fig. 4C2).

10. The callose of the tetrad degraded, and the microspores were released. At this moment, the microspores released by the same tetrad were not totally separated, and the nucleus of each microspore was centrally located (Fig. 4C3).

11. The microspores formed large vacuoles, and the nucleus was located at the cell margin. The tapetum layer degraded, releasing the Ubisch body (Fig. 4C4).

12. The microspores divided asymmetrically to form one large and one small dual-nucleus structure; these structures were the nutrient nucleus and the reproductive nucleus, respectively. Meanwhile, the tapetum layer continued to degrade (Fig. 4D1).

13. The microspores matured, revealing dense nuclei. The tapetum and the middle layer were already degraded, leaving only traces. The endothecium radially thickened (Fig. 4D2), and stomium cells were formed (Fig. 4D3).

14. The pollen sac dehisced from the stomium cells, releasing mature pollen grains (Fig. 4D4).

The sterile plants underwent three types of petalization. The partially petalized type had both fully petalized and normal pollen sac areas. However, the anthers of the partially petalized type were mainly divided into petaloid areas and pollen sac areas.

In this study, we attempted to take the partially petalized type containing two areas as the object to describe and study. The stamen primordium of the sterile plants formed inner, middle, and outer cell layers (Fig. 5A1). However, in the second stage, L2 on the upper part of the anther failed to form sporogenous cells with normal division functions. Sporogenous cells mainly divided vertically (axially), centering on the ovary and inhibiting periclinal division, preventing pollen sacs from forming and causing the flattened anthers (Fig. 5A2 and A3). In subsequent development, the anthers remained flat (Fig. 5A4). The division activity was maintained only at the ends of the cross section and appeared dark in the image staining (Fig. 5B1 and B2). When the anthers matured, the areas looked like petals (Fig. 5B3), with vascular bundle structures similar to those of petals (Fig. 5B4 and C4). Four asymmetric pollen sacs could be formed near the filament end in the lower part of each anther (Fig. 5C1), and the two pollen sacs close to the ovary side were larger than the outer pollen sacs (Fig. 5C2 and C3). However, all pollen sacs had sporogenous cells that were capable of further development. In stages 6 to 7 , when the callose enveloping the pollen mother cell was degraded, irregular shapes appeared, indicating that abnormal degradation of callose might exist (Fig. 5D1). At stage 10, blank areas appeared in the tapetum cells. The blank areas might have been vacuoles, leading to the premature degradation of the tapetum (Fig. 5D2). At this time, some anthers had only two pollen sacs left. The pollen sacs on the outside shrank and disappeared (Fig. 5D3). In stage 13, the petalized anthers could form stomium cells, the endothecium was radially thickened (Fig. 5D4 and E4), and the pollen grains in the lower pollen sac were stained in different shades (Fig. 5E1). A noticeable generative nucleus and a mass of chromosomes without noticeable nuclear structure were observed (Fig. 5E2 and E3). This phenomenon shows that the fertility of the pollen produced by the anthers of the sterile plants was not uniform, and the pollen traits need to be tested.

Differences BetweEn the peTal aReas of PETALIZed aborTION ANTHER AND THE PETAL STRUCTURE. SEM revealed that the abaxial surface epidermal cells of the petalized anthers of the male sterile plants had darker shadows than those of the petals (Fig. 6A1 and B1). In terms of their microstructure, the epidermal cells of the petals were flatter and less undulating than those of the anthers. The parenchyma cells were mainly occupied by large central vacuoles at pollen maturity. As a result, the nuclei were often invisible or squeezed to the edges of the cells (Fig. $6 \mathrm{~B} 2$ ). The epidermal cells of the fully petalized anthers were characterized by large undulations. The parenchyma cells were mainly occupied by the large central vacuole, and the nucleus was large and obvious (Fig. 6A2).

OBSERVATION OF DiFFERENCES IN POLLen TRAITS. The pollen grains of the fertile $C$. oleifera plants were observed to be full and display regular morphology at the maturity stage (Fig. 7A1). The three germinal furrows were isopolar or radially symmetric (Fig. 7A2 and $\mathrm{A} 3$ ). The equatorial axis lengths $(\mathrm{P})$ ranged from 45.86 to $56.10 \mu \mathrm{m}$, with an average length of $51.23 \mu \mathrm{m}$. Therefore, the pollen belonged to the large-grained pollen class. The polar axis lengths (E) ranged from 18.07 to $27.41 \mu \mathrm{m}$, with an 


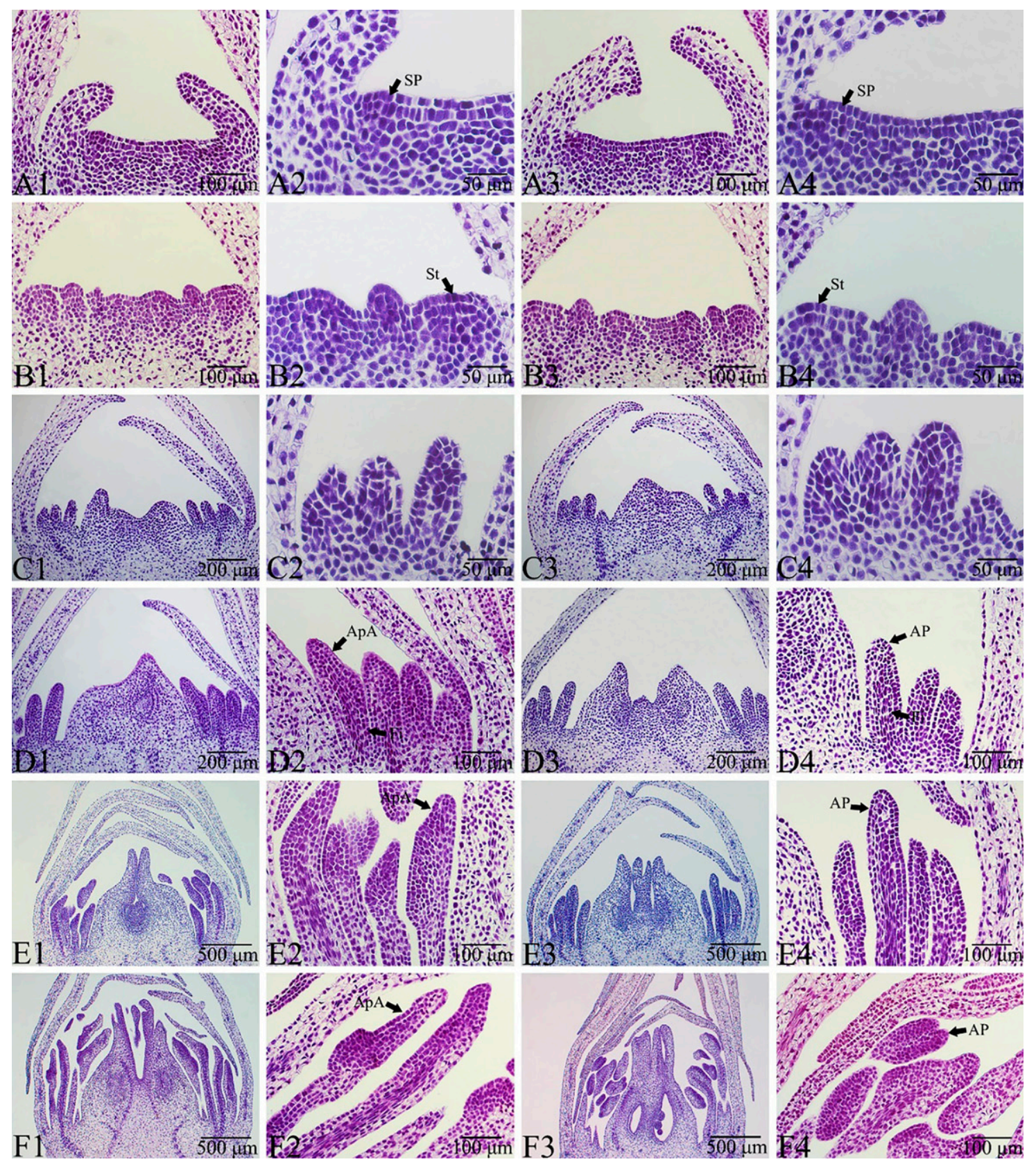

Fig. 3. Differences in the microstructures of stamen differentiation between sterile and fertile male Camellia oleifera plants. (A1-A4) Longitudinal elongation of stamen primordium. (B1-B4) One or two rings of growth of stamen primordium. (C1-C4) Three rings of growth of stamen primordium. (D1-D2) The upper part of the stamens of male sterile plants showed signs of flattening. (D3-D4) Anthers and filament prototypes differentiated from the stamens of fertile plants. (E1-E2) Flattening of the upper parts of the anthers of male sterile plants. (E3-E4) Obvious boundaries between the anthers and filaments of fertile plants. (F1-F2) Further flattening of the anthers of male sterile plants. (F3-F4) Pollen sacs and connective tissues differentiated from the anthers of fertile plants. $\mathrm{SP}=$ stamen primordium, $\mathrm{St}=$ stamen, $\mathrm{AP}=$ anther primordium, $\mathrm{Fi}=$ filament, $\mathrm{ApA}=$ anther-petal abortion.

average length of $24.59 \mu \mathrm{m}$. The $\mathrm{P} / \mathrm{E}$ values ranged between 1.87 and 2.68 , with a mean of 2.10 . The ornamentation of the outer pollen wall displayed a ripple shape (Fig. 7A4). The ornamentation was composed of net ridges and holes. The net ridges protruded, and the holes were irregular in shape.

The mature pollen grains in the partially petalized anthers of male sterile plants displayed irregular inward depressions from three germinal furrows (Fig. 7B3), and the morphologies presented different characteristics along with different degrees of depression (Fig. 7B1), with no polarity or symmetry (Fig. 7B2 and B3). A small number of threaded pollen grains was also observed (Fig. 7B1). The ornamentation of the outer pollen wall displayed a ripple shape. Affected by the depressions, the net holes were smaller than the pollen grains of the fertile plants (Fig. 7B4).

The TTC method was used to detect pollen vitality (Table 2). The pollen vitality of the very small numbers of normal anthers of male sterile plants was $61.12 \%$, lower than the $85.54 \%$ found for fertile plants, and their relative vitality was $66.84 \%$. The vitality of the partially petalized anthers of male sterile plants 


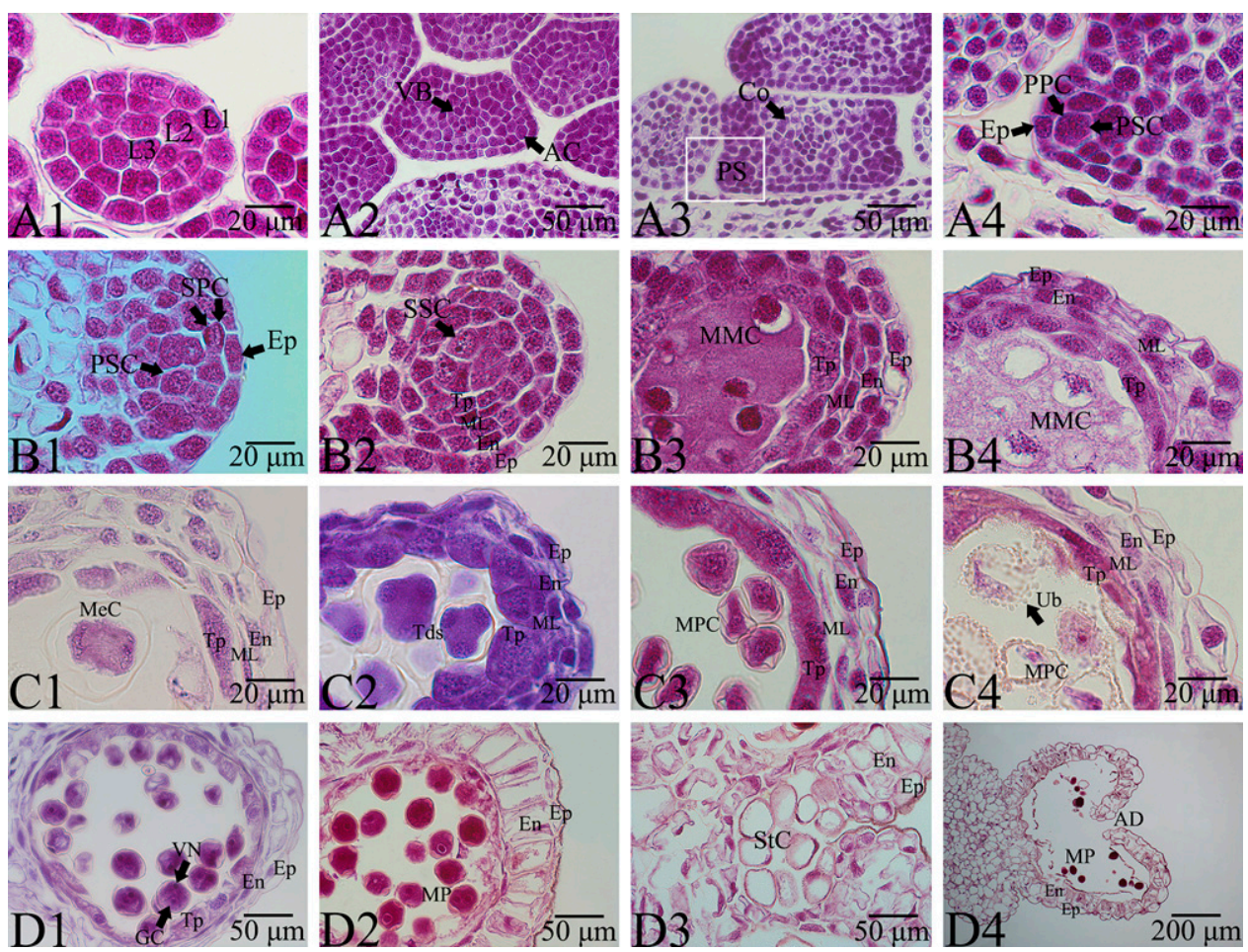

Fig. 4. Anther development of the fertile male Camellia oleifera plant. (A1) Formation of the stamen primordium in the fertile male plant (cross section) that contained three layers (labeled L3, L2, L1 from the inside to the outside). (A2) The stamen primordium underwent vigorous differentiation centered on the four corners, and sporogenous cells with a large nucleus could be observed. (A3) The L3 layer was differentiated into the connective tissue, and primary sporogenous cells and primary parietal cells were produced through the mitosis of the sporogenous cells, which formed two layers of the anther wall. (A4) Local enlargement of the box in the A3. (B1) The primary parietal cells underwent mitosis to produce two layers of secondary parietal cells, which formed three layers of anther parietal cells with the epidermis, and the differentiation of primary sporogenous cells produced secondary sporogenous cells. (B2) The two secondary parietal cell layers underwent mitosis to form five layers of anther parietal cells, which were the epidermis (one layer), endothecium (one layer), middle layer (two layers), and tapetum layer (one layer) from the outside to inside, respectively. (B3) The secondary sporogenous cells underwent mitosis to form pollen mother cells that were surrounded by callose. (B4) Callose underwent the first degradation, which was manifested by light staining, and it released single pollen mother cells for meiosis. (C1) The pollen mother cell completed meiosis I. (C2) The pollen mother cell completed meiosis II, and a tetrad would be formed later. (C3) The tetrad callose underwent degradation, and released microspores, whose nucleus was located in the center. (C4) Microspore vacuoles were formed and the nucleus was pushed to the margin of the cell; the tapetum layer began to degrade, releasing Ubisch bodies (indicated by the arrow). (D1) The microspores divided asymmetrically to form one large and one small dual-nucleus structure, which were the nutrient nucleus and the reproductive nucleus, respectively. (D2) The microspores matured, whose staining was deepened compared with those in D1; the tapetum and middle layers were already degraded, and the endothecium radially thickened. (D3) Stomium cells were formed. (D4) The anther was dehisced from the stomium cells, releasing mature pollen grains. $\mathrm{VB}=$ vascular bundle; $\mathrm{AC}=$ archesporial cell; $\mathrm{Co}=$ connective; $\mathrm{PSC}=$ primary sporogenous cell; $\mathrm{Ep}=$ epidermis; $\mathrm{PPC}=$ primary parietal cell layer; $\mathrm{SPC}=$ secondary parietal cell layer; PSC $=$ primary sporogenous cell; $\mathrm{SSC}=$ secondary sporogenous cell; $\mathrm{Tp}=$ tapetum; $\mathrm{ML}=$ middle layer; $\mathrm{En}=$ endothecium; $\mathrm{MMC}=$ microspore mother cell; $\mathrm{MeC}=$ meiotic cell; $\mathrm{Tds}=$ tetrads; $\mathrm{MPC}=$ microspore parietal cell; $\mathrm{Ub}=\mathrm{ubsite} ; \mathrm{VN}=$ vegetative nucleus; $\mathrm{GC}=$ generative cell; $\mathrm{MP}=$ mature pollen; $\mathrm{StC}=$ stomium cell; $\mathrm{AD}=$ anther dehiscence .

germination method was $7.96 \%$ higher than that obtained by the TTC method (11.20\% to $3.24 \%$ ). Pollen with low vitality still has the possibility of germination; this result also reveals that the causes of abortion are diverse during the development of anthers in sterile plants, resulting in different pollen vitality rates.

\section{Discussion}

Male sterility in plants often manifests as the lack of pollen formation, anther deformities, or nonviable pollen. Pollen abortion can occur in every stage of the anther development process, and different species show different manifestations (Laser and Lersten, 1972). It has been found that anther browning and petaloid anthers exist in male sterile plants of the Camellia genus (Jiang et al., 2020; Xiong et al., 2019). These two abortion means are also the main routes of abnormal anther development in other plants (Kozik et al., 2012). In a study describing petalized anther sterility, the abortion of $A$. schoenoprasum revealed smaller anthers in sterile plants compared with the control group, no radial thickening of the endothecium, the inability of sterile plants to release pollen, and the absence of viable pollen in pollen sacs that were the same color as the petals (Engelke et al., 2002). In the Ogura cytoplasmic male sterile line of B. juncea, the stamens showed a petal structure, yet no pollen sacs were produced (Meur et al., 2006).

The development of $C$. oleifera anthers has been previously studied (Gao et al., 2015a; Yuan et al., 2011); however, the sporogenous

reached $11.19 \%$, and their relative vitality was $3.24 \%$. The fully petalized anthers did not produce pollen. Therefore, their vitality was 0 .

In vitro germination was used to detect the pollen germination rate (Table 2). The in vitro germination rate of the pollen produced by the anthers of the normal fertile plants was $51.14 \%$. The in vitro germination rate of the pollen produced by normal anthers on male sterile plants was $43.19 \%$, with a relative germination rate of $79.00 \%$. The in vitro germination rate of pollen produced by partially petalized anthers was $23.10 \%$, and their relative germination rate was $11.20 \%$. As fully petalized anthers did not produce pollen, their germination rate was 0 . The pollen vitality of the partially petalized anthers obtained in the in vitro cell stage was not included in either of these two studies. For this purpose, this study conducted a brief cytological description ranging from the development of the stamen primordium to the completion of pollen dispersion and divided this development process into 14 stages. Although resin embedding can help observe cell morphology clearly, its tedious procedures often result in an insufficient division of the number of anther development stages, which may lead to the lack of reference this study bears to mutants that were found later (Gao et al., 2015b; Kim et al., 2016). In contrast, the procedures of paraffin sectioning are much simpler, and the sections can be prepared in a large amount. Therefore, this method will be more helpful and more exact in dividing different stages of anther development. In this 

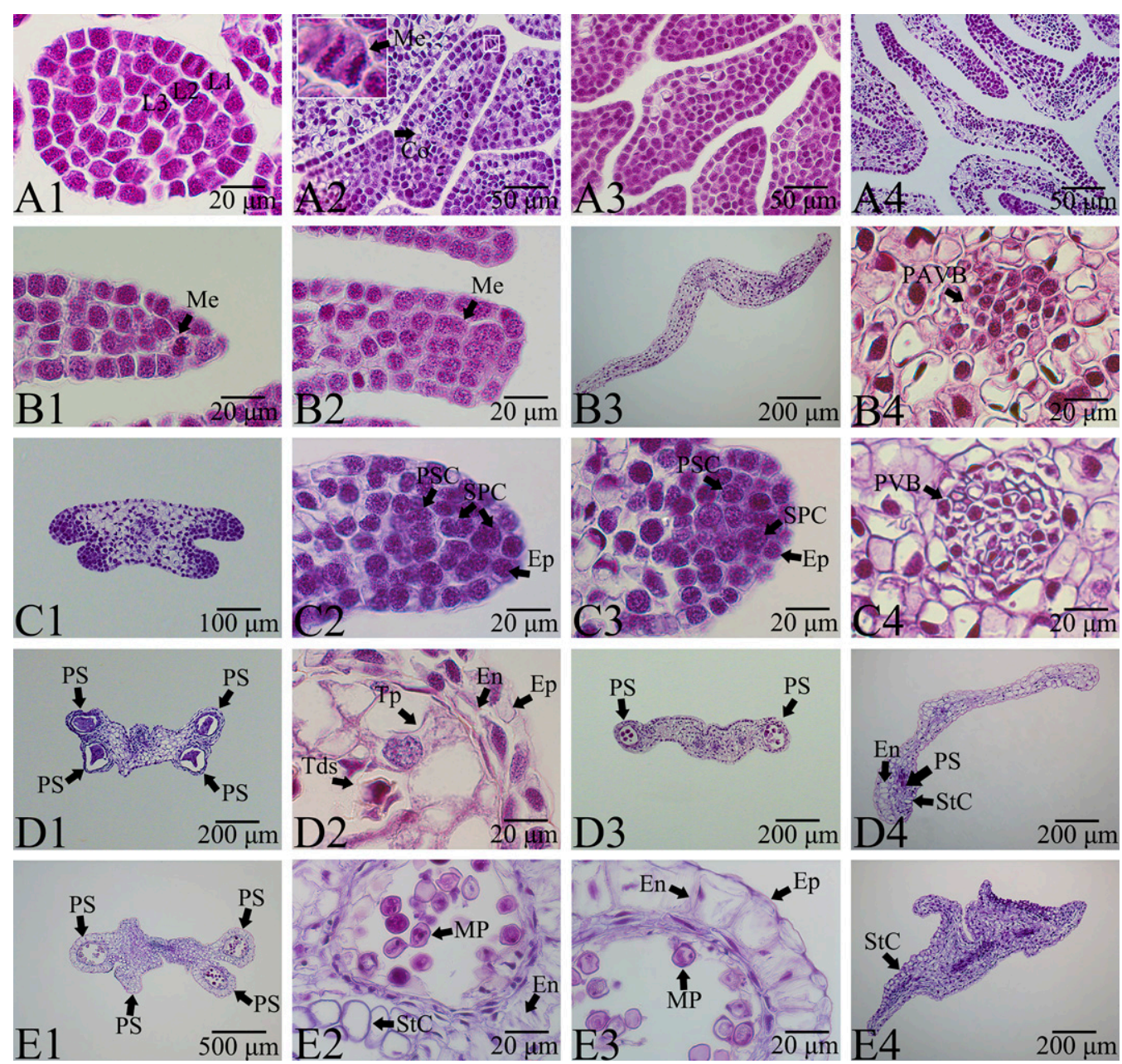

Fig. 5. Anther development of the male sterile Camellia oleifera plant. (A1) The stamen primordium was formed (cross section). (A2) The anther underwent anticlinal division centered on the ovary. (A3) The enlargement of the box in A2. (A4) The cross section of the petalized anther. (B1-B2) The cytoplasm of the cells at both ends of the cross section of the petalized anther was dense, and the cells were in a division state. (B3) The late development stage of the petalized anther. (B4) The vascular bundle in the petalized region of the anther. (C1) Four pollen sacs were formed in the lower part of the partially petalized anther. The sacs near the ovary were large while those on the opposite side were small, showing asymmetric development. (C2) The pollen sac of the petalized anther close to the ovary. (C3) The pollen sac of the petalized anther distant from the ovary. (C4) The vascular bundle of the petal. (D1) In stage 7 , the callose enveloping the pollen mother cell showed irregular shrinkage. (D2) In stage 10, blank areas appeared in the tapetum cells. (D3) In Stage 10, in some anthers, only two pollen sacs developed. (D4) In stage 13, stomium cells differentiation occurred in the upper part of the fully petalized anther and the endothelium of the anther chamber was radially thickened; the staining of the anther chamber was deeper compared with other regions. (E1) In stage 13, three pollen sacs were observed with a normal structure, but the pollen grains were missing, which led to uneven staining. (E2) In stage 13, unevenly stained pollen grains. (E3) In stage 13, slightly stained pollen grains. (E4) In stage 13, stomium cells differentiation occurred in the lower part of the anther and the endothelium of the anther chamber was radially thickened. $\mathrm{Me}=$ meristem; $\mathrm{Co}=$ connective; $\mathrm{PVAB}=$ petalized anther vascular bundle; PSC $=$ primary sporogenous cell; SPC = secondary parietal cell layer; Ep = epidermis; PVB = petal vascular bundle; PS = pollen sac; En = endothecium; $\mathrm{Tp}=$ tapetum; $\mathrm{Tds}=$ tetrads; $\mathrm{MP}=$ mature pollen; $\mathrm{StC}=$ stomium cell. process of meiosis (Sheridan et al., 1999). In the subsequent development stages, anticlinal division was maintained only on the ends of the cross section in the petaloid area of anthers. The development of petaloid anthers was described as the development of the connective tissue of the anthers (Xiong et al., 2019), resulting from the high-frequency division of the middle and peripheral anther cells (He et al., 2010). However, in this study, the cells in the middle of the anthers were lightly stained, while the cells at both ends were darkly stained, indicating that the nuclei of the cells at both ends were active and more cells were observed to be in the division phase in these areas. Therefore, we thought that the cell division frequency was higher at both ends than in the middle. The dividing cells underwent mitosis to form two cells. The cells toward the middle of the anther developed and differentiated into parenchymal cells (which partially developed into vascular bundles), and the cells at both ends maintained robust division states. However, the division status of the nucleus, as well as detailed organelle failure, cannot be clearly observed on paraffin sections, which constitute a limitation of the paraffin-sectioning technique. To disclose these mysteries, ultrathin sectioning involving resin embedding needs to be performed.

The lower parts of the anthers of the male sterile plants examined in this study study, specimen abortion mainly occurred in the second stage of male sterile plants (HB-21) of C. oleifera. The L2 layer failed to form normal sporogenous cells, causing flat petalization on the upper part of the anthers. In mscal maize mutants, the anthers almost did not differentiate sporogenous cells, and the anthers were composed of massive parenchymal tissues, similar to vascular bundles, but could differentiate into anther wall structures (Chaubal et al., 2003). Mac1 plants experienced excessive division after the formation of sporogenous cells; however, most of them did not form pollen mother cells. Even if pollen mother cells were formed, these pollen mother cells could not complete the could form pollen sacs and differentiate into sporogenous cells. One of the characteristics of sporogenous cells undergoing mitosis to form pollen mother cells is that the pollen mother cells are surrounded by common callose walls (Gao et al., 2015a) that are each composed of a layer of $\beta$-1,3-glucan (Liu et al., 2015), believed to prevent the fusion of the pollen mother cells (Waterkeyn, 1962), and synthesized by callose synthase (Chen and Kim, 2009). The callosum wall thickens and subsequently degrades after the pollen mother cell stage occurs (the cytoplasm is darkly stained) (Li et al., 2006), releasing a single pollen mother cell wrapped in callose. This first degradation phenomenon was also described in Juncus (Lopes et al., 

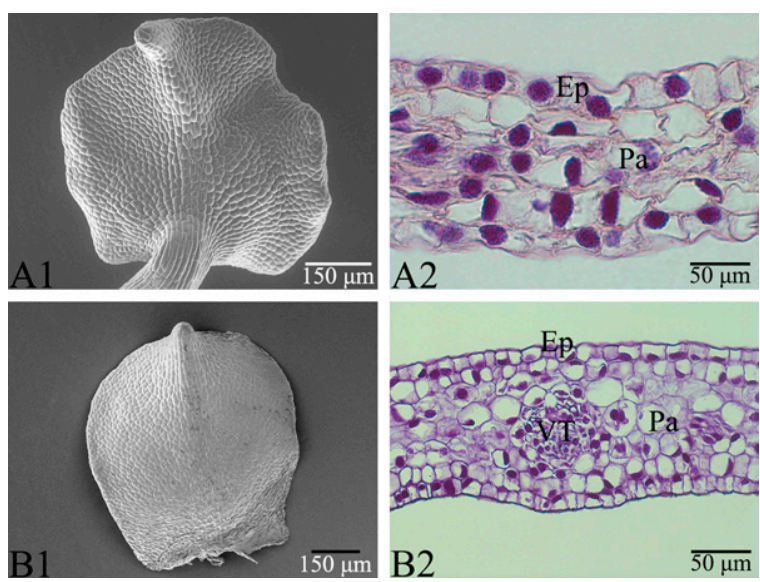

Fig. 6. Differences between the morphological structures of petalized anthers and petals of male sterile Camellia oleifera plants. (A1) Petalized anthers. (A2) Microstructure of the petal area of petalized anthers (paraffin section, cross section). (B1) C. oleifera petals at the same period as that shown in A1. (B2) The microstructure of a petal cross section (paraffin section). Ep $=$ epidermis; $\mathrm{VT}=$ vascular tissue; $\mathrm{Pa}=$ parenchyma.

2020). After meiosis, pollen mother cells form a tetrad surrounded by callose, and then the callose wall is decomposed by $\beta$-1,3-glucanase secreted by the tapetum layer to release the microspores (Wan

et al., 2011). The callose wall has two main degradation opportunities to maintain meiosis. The delayed degradation of callose has been observed to result in the delayed release of microspores, causing the abortion of Lilium brownii and Oryza sativa (Wan et al., 2011; Wang et al., 2019). The premature degradation of callose also caused Nicotiana tabacum microspores to have very thin cell walls and degenerate, causing male sterility (Worrall et al., 1992). However, in this study, the abnormality of the callose wall of the sterile $C$. oleifera male plants occurred at the first degradation stage, and the pollen mother cells wrapped by callose walls showed irregular shrinkage; these abnormalities may have arisen when the tapetum secreted callose synthase.

The tapetum cells, which are closely adjacent to the microspores, belong to the anther wall cells. In the case of mutation of the Arabidopsis thaliana TPD1 gene, tapetum cells differentiate into microspores in situ, resulting in an increase in the number of microspores, indicating that tapetum cells are closely related to microspores (Yang et al., 2003). The main function of the tapetum on the microspores is to provide the latter with callose synthase, nutrients, and sporopollenin and to facilitate degradation in a timely manner $(\mathrm{Hu}$, 2005). In this study, when primary degradation of the callose wall occurred, the tapetum layer should have developed further to ensure the progression of meiosis. However, the tapetum layers in the sterile plants were shaped like a ribbon, similar to the middle layer, resulting in the abnormal
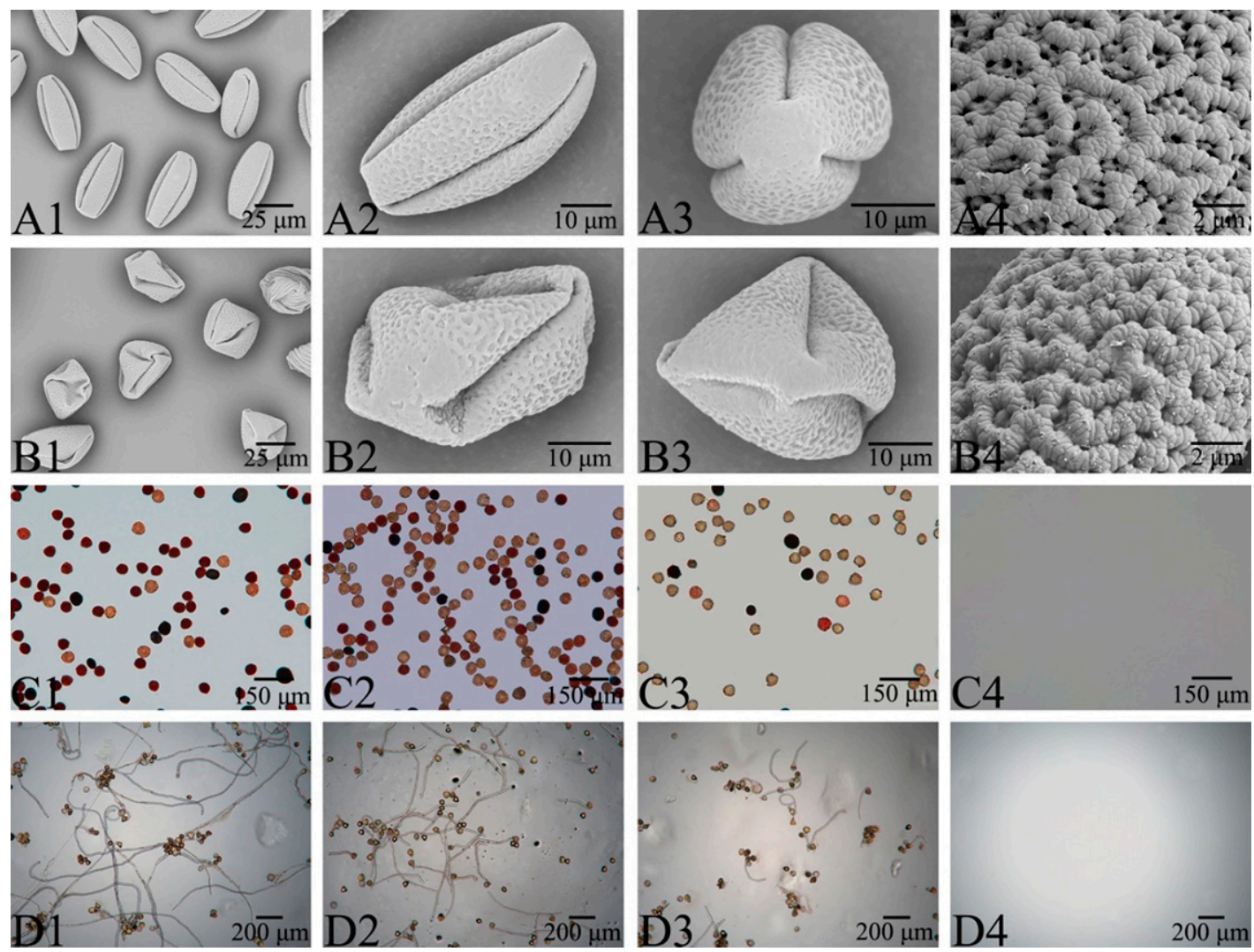

Fig. 7. Differences in pollen traits between sterile and fertile male Camellia oleifera plants. (A1) Pollen grains of fertile plants (A2-A3) Equatorial and polar views of a single pollen grain of a fertile plant. (A4) The ornamentation on the outer wall of a pollen grains of a fertile plant. (B1) Pollen grains of male sterile plants. (B2-B3) Equatorial and polar views of a single pollen grain of a male sterile plant. (B4) The ornamentation on the outer wall of the pollen grain of a male sterile plant. (C1) Pollen vitality of fertile plants tested by the triphenyltetrazolium chloride (TTC) method. (C2) Pollen vitality in the unpetalized anthers of male sterile plants. (C3) Pollen activity in the partially petalized anthers of male sterile plants. (C4) No pollen in the fully petalized anthers of male sterile plants determined in the pollen vitality test. (D1) In vitro pollen germination of the anthers of fertile plants. (D2) In vitro pollen germination of the unpetalized anthers of male sterile plants. (D3) In vitro pollen germination of the partially petalized anthers of male sterile plants. (D4) In vitro pollen germination of the fully petalized anthers (no pollen) of male sterile plants. shrinkage of the pollen mother cells; this characteristic indicates that the integrity of the structure is a prerequisite for normal anther functioning. After the pollen of $C$. oleifera matures, the inclusions feature lipid droplets. Nutrient transfer and transformation exist during the development of the anther (Wei et al., 2013); however, whether abnormalities in nutrient transfer and transformation occur in the anthers of sterile $C$. oleifera plants remains to be investigated.

The timely degradation of the tapetum layer can release the cell inclusions of the tapetum layer into the anther cells (Parish and $\mathrm{Li}, 2010$ ); however, its delayed degradation caused $C$. oleifera and Camellia crassocolumna to be unable to form viable pollen (Jiang et al., 2020; Xiong et al., 2019). This premature degradation also led to the occurrence of male sterility in rice (Shi et al., 2009). In this study, the tapetum 
Table 2. Pollen vitality and germination rates of Camellia oleifera.

\begin{tabular}{|c|c|c|c|c|}
\hline \multirow[b]{2}{*}{ Index } & \multicolumn{4}{|c|}{ Anther type } \\
\hline & Fertile plant & Normal sterile & Partially petalized & Fully petalized \\
\hline \multicolumn{5}{|l|}{ Vitality } \\
\hline TTC $(\%)$ & 85.54 & 61.12 & 11.19 & 0 \\
\hline Vital pollen (no.) & 3114 & 2081 & 101 & 0 \\
\hline Relative vitality (\%) & 100.00 & 66.84 & 3.24 & 0.00 \\
\hline In vitro germination rate $(\%)$ & 51.14 & 43.19 & 23.10 & 0.00 \\
\hline In vitro germinations (no.) & 1862 & 1470 & 208 & 0 \\
\hline Relative germination rate $(\%)$ & 100.00 & 79.00 & 11.20 & 0.00 \\
\hline Image & Figure 7D1 & Figure 7D2 & Figure 7D3 & Figure 7D4 \\
\hline
\end{tabular}

TTC $=$ triphenyltetrazolium chloride.

layer of the anthers in fertile $C$. oleifera plants involved in the in situ degradation belonged to the glandular tapetum (Pacini et al., 1985). This layer was degraded in stage 13 (pollen maturation) in this study, and there were signs of premature degradation of the tapetum layer in the sterile plants. At stage 10, white areas were found in the cells of the tapetum layer. The tapetum layer may have gone through vacuolization and degraded three stages earlier, resulting in a decrease in the nutrients required for the development of microspores and thereby impacting the fertility of pollen. In ultrastructure cytochemistry, $\mathrm{Ca}^{2+}$ was found to play an essential role in regulating the reproductive process of $C$. oleifera. The development of $C$. oleifera microspores is accompanied by the transfer of $\mathrm{Ca}^{2+}$ between anther wall cells and microspores, which is closely related to the formation of $C$. oleifera microspore vacuoles; the distribution and transfer of $\mathrm{Ca}^{2+}$ in the anthers of male sterile plants in this study remain to be further investigated (Wei et al., 2015).

In fertile $C$. oleifera plants, the pollens appear full, the ornamentation of the outer walls is ripple-like, and the net holes are irregular; pollen vitality is not significantly correlated with pollen structure (Deng et al., 2020). However, the cell inclusions are missing in the pollen grains of sterile plants, causing the pollen grains to depress inward from the germinal furrows. As a result, the pollen grains are irregular in morphology and lose vitality; however, no significant changes occur in the ornamentation of the outer walls. In contrast, in $A$. thaliana ms-188, the remaining pollen grains lacked ornamentation of the outer wall (Zhang et al., 2007). There were distinct differences in the diameters of pollen grains between the sterile and fertile plants due to differences in the inclusion contents. In the anther of the sterile plant, threaded pollen grains were observed. This type of grains has also been reported in literature (Wang, 2011). Due to an extremely small number, these grains were difficult to isolate for further research in this study. The reasons for the formation of these grains have not been investigated, according to literature searches. The $\mathrm{F}_{1}$ generation produced by the interspecific crossing of 'Huashuo' and Camellia yuhsienensis cultivar Youza 2 showed chromosomal abnormalities in the meiosis stage, resulting in a wide range of variations in the pollen grain diameter $(\mathrm{Li}$ et al., 2021). Whether abnormalities occur when the pollen mother cells of sterile plants undergo meiosis and the degree of abnormality call for further research. The production of inactive pollen is one of the important manifestations of male sterility, and the sterility severity needs to be determined (Alexander, 1969). However, the procedures of different determination approaches can vary greatly according to the principles they are based on. To make a comparison between our results and those in literature (Deng et al., 2020; Wang et al., 2012; Zhao et al., 2021), we used the TTC and in vitro germination methods to determine the pollen vitality of the sterile plant and fertile plant. The combining results based on these methods can be more persuasive, considering that the results based on them are often inconsistent with each other. According to our results, the 'Huashuo' fertile plant had an in vitro germination rate of $51.14 \%$, whereas the TTC-based result was $85.54 \%$. These results are close to those reported in the literature (Deng et al., 2020; Wang et al., 2012; Zhao et al., 2021). In the sterile C. oleifera plants, the pollen vitality obtained by the TTC method was inconsistent with that obtained by the in vitro germination method, and a combination of these two methods can better explain the obtained pollen vitality. The pollen germination rate of the fertile 'Huashuo' plants was $51.14 \%$, which was similar to the results of most studies on the germination rate of ordinary C. oleifera (Deng et al., 2020; Zhao et al., 2021). The fully petalized anthers of male sterile plants did not produce pollen. The pollen vitality produced by the partially petalized anthers was much lower than that of fertile plants, although these plants were not completely sterile, as has also been reported before (Chen et al., 2011; Xiong et al., 2019). After pollen mother cells complete meiosis, pollen grains are formed, which inaugurates the initiation of another unique cell division process, that is, asymmetric division. By the asymmetric division, a large vegetative cell and a small generative cell are formed. The large vegetative cell contains dispersed chromatin, which constitutes most part of the cytoplasm of pollen grains, whereas the small generative cells contains condensed chromatin (Twell et al., 1998). Asymmetric division plays a crucial role in the double fertilization and seed development of $C$. oleifera (Gao et al., 2015b). In this study, during the asymmetric mitosis of the pollen grain of the petalized anther, a noticeable, deeply stained nucleus (generative nucleus) and a mass of slightly stained chromosomes without noticeable nuclear structure were observed, which were remarkably different from the generative and vegetative nuclei in normal pollen grains. In addition, according to our experiment, the length of the pollen tubes germinated from the pollen grains produced by the petalized anther after the same time of in vitro 
germination was noticeably shorter than that of the normal pollen tubes. Presumably, during the asymmetric mitosis of the pollen grain of the partially petalized anther, the vegetative nucleus fails to be formed, which results in insufficient nutrients required for germination, thereby deterring the pollen grain from germinating or slowing down the growth rate of the pollen tube.

Colletes gigas is one of the main pollinators of $C$. oleifera. It can easily carry pollen when collecting nectar from $C$. oleifera, but pollen from $C$. oleifera is toxic to bee larvae (Xie et al., 2013). The pollen produced by male sterile 'Huashuo' plants is not only small but is also low in vitality. When used as the main cultivar, it is planted with pollinizers at a ratio of 4:1 (Tan et al., 2011); this combination not only effectively avoids the occurrence of $C$. oleifera self-incompatibility and reduces the selfing probability, but also wins the favor of pollinating insect populations for male sterile plants. In terms of cultivar selection, the pollen xenia effect can be further used to improve the fruit-setting rate and fruit quality of $C$. oleifera, providing a new method for the efficient production of $C$. oleifera.

Male sterile plants are often used in breeding because they do not require emasculation, allowing male parent selection under natural pollination at the lowest cost to obtain more breeding materials and speed up the selection of new cultivars. In the field of agricultural production, unstable sterile plants need to be backcrossed and purified for multiple generations before they can be used in breeding (Kozik et al., 2012). However, for C. oleifera, a woody plant, such a breeding production cycle is excessively long. However, the seed-setting rate of selfed $C$. oleifera is extremely low, and the purity of $F_{1}$ generation seeds is guaranteed to a certain extent. However, whether $F_{1}$ generation seeds can be directly applied for breeding requires further investigation. To ensure the purity of the hybrid offspring of male sterile plants, it is imperative to further probe the physiological changes and molecular biological mechanisms of male sterile plants to achieve complete sterility for the $\mathrm{F}_{1}$ generation of sterile plants and increase the seed purity and production potential.

\section{Literature Cited}

Ai, Y., Y. He, Y. Hu, Q. Zhang, C. Pan, and M. Bao. 2014. Characterization of a novel sterile male mutant of Tagetes patula induced by heat shock. Euphytica 200(2):159-173, https://doi.org/10.1007/ s10681-014-1116-2.

Alexander, M.P. 1969. Differential staining of aborted and nonaborted pollen. Stain Technol. 44(3):117-122.

Bulant, C. and A. Gallais. 2000. Xenia effects in maize with normal endosperm: I. Importance and stability. Crop Sci. 38(6):182-189, https://doi.org/10.2135/cropsci1998.0011183X003800060019x.

Carlsson, J. and K. Glimelius. 2011. Cytoplasmic male-sterility and nuclear encoded fertility restoration, p. 469-491. In: F. Kempken (ed.). Plant mitochondria. Springer, New York, NY.

Chaubal, R., J.R. Anderson, M.R. Trimnell, T.W. Fox, M.C. Albertsen, and P. Bedinger. 2003. The transformation of anthers in the mscal mutant of maize. Planta 216(5):778-788, https://doi.org/ 10.1007/s00425-002-0929-8

Chen, X.Y. and J.Y. Kim. 2009. Callose synthesis in higher plants. Plant Signal. Behav. 4(6):489-492, https://doi.org/10.4161/psb.4.6.8359.

Chen, Y., D. Wang, Y. Liu, S. Peng, L. Su, and L. Chen. 2011. Research on selection of superior male-sterile clone of Camellia oleifera. J. Central South Univ. For. Technol. 31(9):1-6, https://doi.org/ 10.1007/s11676-011-0141-4

Deng, Q., J. Li, C. Gao, J. Cheng, X. Deng, D. Jiang, L. Li, and P. Yan. 2020. New perspective for evaluating the main $C$. oleifera cultivars in
China. Sci. Rep. 10(1):1-14, https://doi.org/10.1038/s41598-020-77 609-7.

Engelke, T., S. Hülsmann, and T. Tatlioglu. 2002. A comparative study of microsporogenesis and anther wall development in different types of genic and cytoplasmic male sterilities in chives. Plant Breed. 121(3):254-258, https://doi.org/10.1046/j.1439-0523.2002.00704.x.

Gao, C., D.Y. Yuan, B.F. Wang, Y. Yang, D.M. Liu, and Z.Q. Han. 2015a. A cytological study of anther and pollen development in Camellia oleifera. Genet. Mol. Res. 14(3):8755-8765, https://doi.org/ 10.4238/2015.July.31.24.

Gao, C., D.Y. Yuan, Y. Yang, D.M. Liu, and F. Zou. 2015b. Pollen tube growth and double fertilization in Camellia oleifera. J. Amer. Soc. Hort. Sci. 140(1):12-18, https://doi.org/10.21273/jashs.140.1.12.

Gao, C., R. Yang, and D.Y. Yuan. 2018. Structural characteristics of the mature embryo sac of Camellia oleifera. Nord. J. Bot. 6:1-13, https://doi.org/10.1111/njb.01673.

He, C., X. Tan, D. Yuan, Q. Hu, and F. Zou. 2009. Determination of the pollen number and pollen germination rate of seven Camellia species. J. Central South Univ. For. Technol. 1:74-78, https://doi. org/10.1007/978-1-4020-9623-5_5.

He, Y.F., Q.Q. Song, and S.P. Chen. 2020. Transcriptome analysis of self- and cross-pollinated pistils revealing candidate unigenes of selfincompatibility in Camellia oleifera. J. Hort. Sci. Biotechnol. 95(1):19-31, https://doi.org/10.1080/14620316.2019.1632749.

He, Y.H., G.G. Ning, Y.L. Sun, Y. Hu, X.Y. Zhao, and M.Z. Bao. 2010. Cytological and mapping analysis of a novel sterile male type resulting from spontaneous floral organ homeotic conversion in marigold (Tagetes erecta L.). Mol. Breed. 26(1):19-29, https://doi.org/ 10.1007/s11032-009-9372-X.

Hu, G.X., C. Gao, X.M. Fan, W.F. Gong, and D.Y. Yuan. 2020. Pollination compatibility and xenia in Camellia oleifera. Hort. Sci. Horts. 55(6):898-905, https://doi.org/10.21273/HORTSCI14933-20.

$\mathrm{Hu}$, S.Y. 2005. Angiosperm peproductive biology (in Chinese). Higher Educ. Press, Beijing, China.

Jia, Z., Y. Liu, X. Chen, H. Wang, Y.J. Deng, X.W. Hu, Y. Zhou, Z.Z. Pang, and H.G. Lai. 2020. Developmental anatomy of flower apparatus of sterile male plant of Camellia vietnamensis. Redai Zuowu Xuebao 41(9):1808-1815, https://d.wanfangdata.com.cn/periodical/rdzw xb202009013.

Jiang, H.B., S.M. Yang, Y.F. Liu, Y.P. Tian, Y.N. Sun, L.B. Chen, and Y.C. Tang. 2020. Biological characteristics and cytological studies on anther abortion of sterile male Camellia crassocolumna. Zuo Wu Xue Bao 46(7):1076-1086, https://doi.org/10.3724/SP.J.1006.2020.94159.

Kim, Y.J., M.G. Jang, L. Zhu, J. Silva, X.L. Zhu, J. Sukweenadhi, W.S. Kwon, D.C. Yang, and D.B. Zhang. 2016. Cytological characterization of anther development in Panax ginseng Meyer. Protoplasma 253(4):1111-1124, https://doi.org/10.1007/s00709-015-0869-3.

Klatt, B.K., A. Holzschuh, C. Westphal, Y. Clough, I. Smit, E. Pawelzik, and T. Tscharntke. 1775. 2014. Bee pollination improves crop quality, shelf life and commercial value. Proc. Biol. Sci. 281:2013 2440, https://doi.org/10.1098\%2Frspb.2013.2440.

Kodad, O. 2008. Fruit quality in almond as related to the type of pollination in self-compatible genotypes. J. Amer. Soc. Hort. Sci. 133(3):320-326, https://doi.org/10.21273/JASHS.133.3.320.

Kozik, E.U., R. Nowak, M. Nowakowska, and B. Dyki. 2012. Level of sterility and morphological flowers differentiation of petaloid male-sterile plants of carrot. J. Agr. Sci. 4(2):187, https://doi.org/ 10.5539/jas.v4n2p187.

Laser, K.D. and N.R. Lersten. 1972. Anatomy and cytology of microsporogenesis in cytoplasmic sterile male angiosperms. Bot. Rev. 38(3):425-454, https://doi.org/10.1007/BF02860010.

Lei, H., S. Su, L. Ma, Y. Wen, and X.N. Wang. 2017. Molecular cloning and functional characterization of CoFT1, a homolog of FLOWERING LOCUS T (FT) from Camellia oleifera. Gene 626:215-226, https://doi.org/10.1016/j.gene.2017.05.044.

Li, N., D.S. Zhang, H.S. Liu, C.S. Yin, X.X. Li, W.Q. Liang, Z. Yuan, B. Xu, H.W. Chu, J. Wang, T.Q. Wen, H. Huang, D. Luo, H. Ma, and 
D.B. Zhang. 2006. The rice tapetum degeneration retardation gene is required for tapetum degradation and anther development. Plant Cell 18(11):2999-3014, https://doi.org/10.1105/tpc.106.044107.

Li, Y., T. Ye, C. Han, Z. Ye, J. Zhang, S. Xiao, and D. Yuan. 2021. Cytogenetic analysis of interspecific hybridization in oil-tea (Camellia oleifera). Euphytica 217(2):1-12, https://doi.org/10.1007/s10681020-02762-Z.

Liao, T., D.Y. Yuan, F. Zou, C. Gao, Y. Yang, L. Zhang, and X.F. Tan. 2014. Self-sterility in C. oleifera may be due to the prezygotic late-acting self-incompatibility. PLoS One 9(6):e99639, https://doi. org/10.1371/journal.pone.0099639.

Liu, H.Z., G.S. Zhang, W.W. Zhu, Q.S. Ba, N. Niu, J.W. Wang, S.C. Ma, and J.S. Wang. 2015. Relationship between male sterility and $\beta$-1, 3-glucanase activity and callose deposition-related gene expression in wheat (Triticum aestivum L.). Genet. Mol. Res. 14:574-584, https://doi.org/10.4238/2015.January.26.12.

Liu, Y.E., P. Liu, S.T. Dong, and J.W. Zhang. 2010. Hormonal changes caused by the xenia effect during grain filling of normal corn and high-oil corn crosses. Crop Sci. 50:215-221, https://doi.org/ 10.2133/cropsci2009.04.0186.

Lopes, F.P., A. Oriani, and A.I. Coan. 2020. Development of the permanent tetrad wall in Juncus L.(Juncaceae, Poales). Protoplasma 258:495-506, https://doi.org/10.1007/s00709-020-01583-0.

Meur, G., K. Gaikwad, S.R. Bhat, S. Prakash, and P.B. Kirti. 2006. Homeotic-like modification of stamens to petals is associated with aberrant mitochondrial gene expression in cytoplasmic sterile male Ogura Brassica juncea. J. Genet. 85(2):133-139, https://doi.org/ 10.1007/bf02729019.

Pacini, E., G.G. Franchi, and M. Hesse. 1985. The tapetum: Its form, function, and possible phylogeny in Embryophyta. Plant Syst. Evol. 149(3-4):155-185, https://doi.org/10.1007/BF00983304.

Pahlavani, M.H. and K. Abolhasani. 2006. Xenia effect on seed and embryo size in cotton (Gossypium hirsutum L.). J. Appl. Genet. 47(4):331-335, https://doi.org/10.1007/BF03194642.

Parish, R.W. and S.F. Li. 2010. Death of a tapetum: A programme of developmental altruism. Plant Sci. 178(2):73-89, https://doi.org/ 10.1016/j.plantsci.2009.11.001.

Sheridan, W.F., E.A. Golubeva, L.I. Abrhamova, and I.N. Golubovskaya. 1999. The macl mutation alters the developmental fate of the hypodermal cells and their cellular progeny in the maize anther. Genetics 153(2):933-941, https://doi.org/10.1016/j.bpj.2015.08.011.

Shi, Y., S. Zhao, and J. Yao. 2009. Premature tapetum degeneration: A major cause of abortive pollen development in photoperiod sensitive genic male sterility in rice. J. Integr. Plant Biol. 51(8):774-781, https://www.docin.com/p-1194458602.html.

Tan, X.F., D.Y. Yuan, J. Yuan, F. Zou, P. Xie, Y. Su, D.T. Yang, and J.T. Peng. 2011. An elite variety: Camellia oleifera 'Huashuo'. Scientia Silvae Sinicae, http://en.cnki.com.cn/Article_en/CJFDTOTAL-LYKE 201112031.htm.

Twell, D., S.K. Park, and E. Lalanne. 1998. Asymmetric division and cell-fate determination in developing pollen. Trends Plant Sci. 3(8):305-310, https://doi.org/10.1016/S1360-1385(98)01277-1.

Wan, L., W. Zha, X. Cheng, C. Liu, L. Lv, C. Liu, L. Lv, C. Liu, Z. Wang, B. Du, R. Chen, L. Zhu, and G. He. 2011. A rice $\beta-1$, 3-glucanase gene Osg1 is required for callose degradation in pollen development. Planta 233(2):309-323, https://doi.org/10.1007/s00425-0101301-z.

Wang X.N. 2011. Research on phenology arid blossom biology of Oil-Tea Camellia (in Chinese). Central South Univ. For. Technol., Changsha, China.

Wang X.N., Y.Z. Chen, R. Wang, C.Y. Zhu, S.F. Peng, L.S. Chen, and L. Ma. 2012. Pollen viability and chapiter receptivity of Camellia oleifera. J. Central South Univ. For. Technol. 32(3):17-22, https://doi.org/10.14067/j.cnki.1673-923x.2012.03.020.
Wang, X., Z. Wu, L. Wang, M. Wu, D. Zhang, W. Fang, F. Chen, and N. Teng. 2019. Cytological and molecular characteristics of pollen abortion in lily with dysplastic tapetum. Hortic. Plant J. 5(6):281-294, https://doi.org/10.1016/j.hpj.2019.11.002.

Waterkeyn, L. 1962. Les parois microsporocytaires de nature callosique chez Helleborus et Tradescantia. Cellule 62:225-255.

Wei, D., C. Gao, and D. Yuan. 2015. Calcium distribution during anther development in oil tea (C. oleifera Abel.). J. Amer. Soc. Hort. Sci. 140(1):88-93, https://doi.org/10.21273/JASHS.140.1.88.

Wei, D.M., C. Gao, and D.Y. Yuan. 2013. Histochemical study of polysaccharides and lipids on the developing anthers of $C$. oleifera Abel. Chin. J. Cell Biol. 35(11):1598-1602, http://en.cnki.com.cn/ Article_en/CJFDTOTAL-DNYX201309012.htm.

Wen, Y., S.C. Su, L.Y. Ma, S.Y. Yang, Y.W. Wang, and X.N. Wang. 2018. Effects of canopy microclimate on fruit yield and quality of Camellia oleifera. Scientia Hort. 235:132-141, https://doi.org/ 10.1016/j.scienta.2017.12.042.

Worrall, D., D.L. Hird, R. Hodge, W. Paul, J. Draper, and R. Scott. 1992. Premature dissolution of the microsporocyte callose wall causes male sterility in transgenic tobacco. Plant Cell 4(7):759-771, https://doi.org/10.1105/tpc.4.7.759.

Xiao, Z., Z. Zhang, and C.J. Krebs. 2015. Seed size and number make contrasting predictions on seed survival and dispersal dynamics: A case study from oil tea Camellia oleifera. For. Ecol. Mgt. 343:1-8, https://doi.org/10.1016/j.foreco.2015.01.019.

Xie, C.T., D.M. Wei, and H.Q. Tian. 2006. Advances in cell biological researches on male sterility of higher plants. J. Plant Physiol. Mol. Biol. 32(1):17-23, http://en.cnki.com.cn/Article_en/CJFDTOTALZWSI200601003.htm.

Xie, Z., X. Chen, and J. Qiu. 2013. Reproductive failure of C. oleiferain the plateau region of China due to a shortage of legitimate pollinators. Intl. J. Agr. Biol. 15(3): https://doi.org/10.1071/AN12292.

Xiong, H., P. Chen, Z. Zhu, Y. Chen, F. Zou, and D. Yuan. 2019. Morphological and cytological characterization of petaloid-type cytoplasmic male sterility in Camellia oleifera. HortScience 54(7):1149-1155, https://doi.org/10.21273/HORTSCI14005-19.

Yang, S., L. Xie, H.Z. Mao, C.S. Puah, W.C. Yang, L.X. Jiang, V. Sundaresan, and D. Ye. 2003. Tapetum determinant1 is required for cell specialization in the Arabidopsis anther. Plant Cell 15(12):2792-2804, https://doi.org/10.1105/tpc.016618.

Yuan, D.Y., F. Zou, X.F. Tan, C.Y. He, J. Yuan, and X.M. Fan. 2011. Flower bud differentiation and development of male and female gametophytes in Camellia oleifera. J. Central South Univ. For. Technol. 31:15-20, http://en.cnki.com.cn/Article_en/CJFDTOTAL-ZNLB2011 03014.htm.

Yuan, L.P. 2017. Progress in super-hybrid rice breeding. Crop J. 5(2):100-102, https://doi.org/10.1016/j.cj.2017.02.001.

Zhang, D.L., L.S. Zhang, R.Q. Zhang, J.F. Yu, B.X. Xie, Y.Z. Chen, and J.M. Ruter. 2008. Teaoil camellia-eastern "olive" for the world. Acta Hort. 769:43-48, https://www.actahort.org/books/769/769_3.htm.

Zhang, Z.B., J. Zhu, J.F. Gao, C. Wang, H. Li, H. Li, H.Q. Zhang, S. Zhang, D.M. Wang, Q.X. Wang, H. Huang, H.J. Xia, and Z.N. Yang. 2007. Transcription factor AtMYB103 is required for anther development by regulating tapetum development, callose dissolution and exine formation in Arabidopsis. Plant J. 52(3):528-538, https:// doi.org/10.1111/j.1365-313x.2007.03254.x.

Zhao, R., X. Hu, D.Y. Yuan, J. Masabni, H. Xiong, and F. Zou. 2021. Orthogonal test design for optimizing culture medium for in vitro pollen germination of interspecific oil tea hybrids. An. Acad. Bras. Cienc. 93(2):e20190431, https://doi.org/10.1590/0001-3765202120190431.

Zhuang, R.L. 2008. C. oleiferain China (in Chinese). China Forestry Publishing House, Beijing, China. 